\title{
Thai Hom Mali Rice: Origin and Breeding for Subsistence Rainfed Lowland Rice System
}

\author{
Apichart Vanavichit ${ }^{1,23^{*}}$ D , Wintai Kamolsukyeunyong ${ }^{3}$, Meechai Siangliw ${ }^{3}$, Jonaliza L. Siangliw ${ }^{3}$, Suniyom Traprab ${ }^{4}$, \\ Siriphat Ruengphayak', Ekawat Chaichoompu', Chatree Saensuk', Ekapol Phuvanartnarubal', \\ Theerayut Toojinda ${ }^{3,5}$ and Somvong Tragoonrung ${ }^{6}$
}

\begin{abstract}
The world-renowned Thai Hom Mali Rice has been the most important aromatic rice originating in Thailand. The aromatic variety was collected from Chachoengsao, a central province, and after pure-line selection, it was officially named as Khao Dawk Mali 105, (KDML105). Because of its superb fragrance and cooking quality, KDML105 has been a model variety for studying genes controlling grain quality and aroma. The aromatic gene was cloned in KDML105, as an amino aldehyde dehydrogenase (AMADH) or better known as BADH2 located on chromosome 8. Later on, all other aromatic rice genes were discovered as allelic to the AMADH. As a selection of local landrace variety found in rainfed areas, the Thai Jasmine rice showed adaptive advantages over improved irrigated rice in less fertile lowland rainfed conditions. Because KDML105 was susceptible to most diseases and insect pests, marker-assisted backcross selection (MABC) was used for the genetic improvement since 2000. After nearly 17 years of MABC for integrating new traits into KDML105, a new generation of KDML105, designated HM84, was developed which maintains the cooking quality and fragrance, and has gained advantages during flash flooding, disease, and insect outbreak.
\end{abstract}

Keywords: Thai Hom Mali, Oryza sativa L, Marker-assisted backcross selection, Gene pyramiding, Amino aldehyde dehydrogenase, Flooding tolerance, Blast resistance, Bacterial blight resistance, Brown planthopper tolerance

\section{Origin and distribution}

Thai Jasmine rice is officially known as Thai Hom Mali rice. Hom Mali local landrace varieties were widely distributed throughout Thailand under a variety of names including 'Khao Hom', 'Hom Mali', and 'Khao Mali'. In 1945, the best Hom Mali local variety was discovered by a farmer in Lam Pradoo district, Chonburi province, and in 1951, 199 panicles of the local variety were selected from a nearby district of Chachearngsoa province for pure line selection (Bureau of Rice Research and Development 2010). Based on its superior physical appearance, cooking quality, and grain aroma, row '105' was selected and officially named "Khao Dawk Mali 4-2-105" or "Khao Dawk Mali 105" or "KDML105" for short. KDML105 was released to farmers in 1959. Thai

\footnotetext{
* Correspondence: vanavichit@gmail.com

${ }^{1}$ Rice Science Center, Kasetsart University, Kamphaeng Saen, Nakhon Pathom 73140, Thailand

${ }^{2}$ Agronomy Department, Faculty of Agriculture at Kamphaeng Saen, Kasetsart University, Kamphaeng Saen, Nakhon Pathom 73140, Thailand

Full list of author information is available at the end of the article
}

Jasmine rice was produced annually at approximately 9 . $4 \mathrm{M}$ ton of paddy rice from 4.3 M ha (Department of Foreign Trade 2014; Varinruk 2017).

KDML105 has a tall, lanky, floppy architecture. The average plant height at harvest is approximately $140 \mathrm{~cm}$. KDML105 has a photoperiod sensitivity that determines its flowering date around October. Specifically, the critical induction signal is the day/night time duration. When day length is shorter than 11:52 h, KDML105 will initiate its floral organ (Kumboonreang 2011). The critical day length for photoperiod sensitivity can be met at the end of September when rainfall is normally heavy. Therefore, the full bloom is normally expected in the last two weeks of October, and harvesting will start in the second week of November every year. This photoperiod sensitivity is considered an adaptive advantage for lowland rainfed rice to survive and produce without irrigation water. 


\section{Review}

In traditional lowland rainfed rice cultivation, farmers ask the rice spirit to protect their crop from flooding or drought during cultivation. KDML105 and its mutagenized counterparts, RD15 and RD6, have been widely cultivated in such a stressful mega-ecosystem which occupies $70 \%$ of the rice area in Thailand (Jongdee et al. 2006). Characterized by fluctuation in rainfall distribution and poor soil fertility, the lowland rainfed area produces the highest quality Jasmine rice. Adaptation to the infertile lowland rainfed area of the northeast is the benefit of this high-quality rice. It is mildly tolerant to drought, salinity, and acid sulfate soil (Bureau of Rice Research and Development 2010). KDML105 is not a well-known drought-tolerant variety, but its adaptability in a rainfed lowland ecosystem was ascribed to the plasticity of the root system under abiotic stresses (O'Toole and Bland 1987). Plasticity describes the ability of roots to respond to soil moisture fluctuation (Banco et al. 2000). Particularly, in a paddy field with hardpan, KDML105 consistently expresses its root growth adaptability to water stress via greater root branching (KanoNakata et al. 2013). Expression of root-branching ability in a shallow soil layer plays an important role in capturing water for rapid recovery from drought stresses and is the key adaptive trait of KDML105 in lowland rainfed conditions (Kano-Nakata et al. 2013).
Most rice is very sensitive to salinity, at a salinity level from $3 \mathrm{dS} \mathrm{m}^{-1}$ (USDA 2013). The salinity at such level affects rice growth by reducing germination rate, plant height, tillering, root growth, and spikelet fertility. At the $\mathrm{EC}_{\mathrm{e}}$ as low as $3.5 \mathrm{dSm}^{-1}$, grain yield loss can be at about $10 \%$ depending on varietal difference (Rice Knowledge Bank, International Rice Research Institute, IRRI). Under a salt-affected area in the NE of Thailand, KDML105 was adaptive to salt-affected area in the NE, where 1 . $84 \mathrm{M}$ ha or $16 \%$ of the lowland rainfed area is classified as an inland saline area ranging from 11 to 35 $\mathrm{dS} \mathrm{m}^{-1}$ (Im-Erb et al. 2013; Arunin and Pongwichian 2015). The saline soil in this area is high in sodium and chloride content and has a sandy soil texture, low organic matter, and minimal fertility (Arunin 1984). Cultivation of KDML105 in this area was located on slightly to moderately salt-affected soils, with ECe of 2-8 dS $\mathrm{m}^{-1}$ (Im-Erb et al. 2013; Arunin and Pongwichian 2015). However, KDML105 is less productive in high $\left(8-16 \mathrm{dS} \mathrm{m}^{-1}\right)$ and very high saline soil (>16 dS $\mathrm{m}^{-1}$ ). Therefore, increasing KDML105 salinity tolerance can help poor farmers to grow this fragrant rice in high-salinity areas.

The plasticity of KDML105 seems to be inherited to its irradiated mutants, RD15 and RD6. These three cultivars occupied $5.5 \mathrm{M}$ ha of the mega-lowland rainfed area mostly in the Northeast of Thailand (Fig. 1). On the

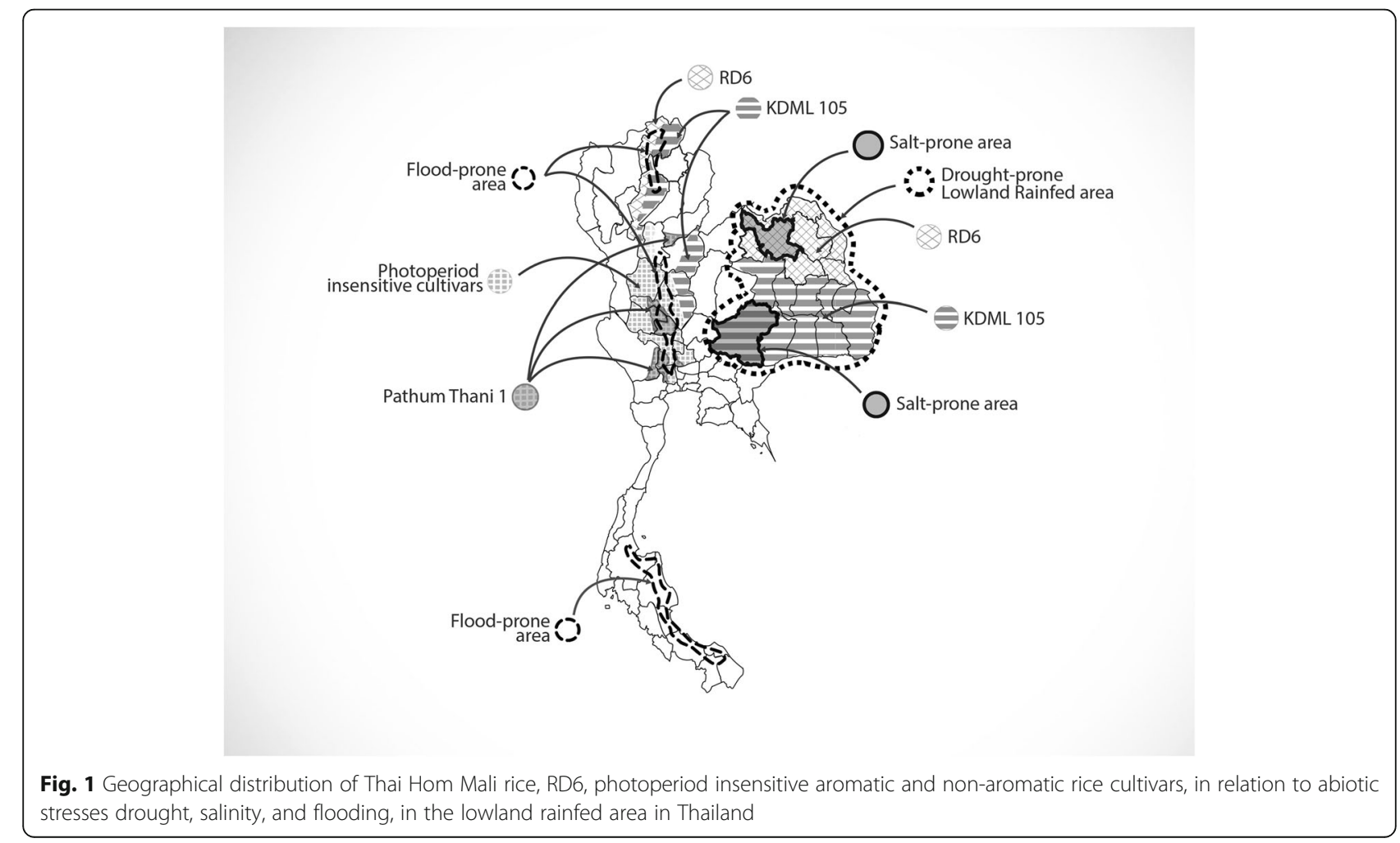


other hand, the three mega-varieties, KDML105, RD15, and RD6, were not successful in the central plain due to the widespread occurrence of various diseases and insect pests in irrigated areas. This implies that the three Jasmine rice varieties are more adaptable to abiotic than biotic stresses. Therefore, breeding for resistance to biotic and abiotic stresses is the most sensible approach to strengthen KDML105 in lowland rainfed and irrigated areas.

\section{Cooking quality, fragrance, and interaction with environment}

The superb cooking quality of KDML105 is characterized by its soft-texture, aromatic, long-slender white rice. Low amylose content, a low degree of gelatinization, and soft gel consistency are biochemical characteristics of the cooked KDML105 rice. When grown in its optimal environment, the physical appearance of polished grains is pearly, clear, very long and slender, with a glossy exterior. The dimension of brown rice is $2.1 \times 7.5 \times 1.8 \mathrm{~mm}$ (width $\mathrm{x}$ length $\mathrm{x}$ thickness), and the length/width ratio is 3.42 . Its head rice yield is $58-60 \%$.

\section{Cooking and eating quality}

Eating quality is determined by consumer preference and perception of cooked rice under an optimal cooking protocol. Cooking quality can be determined as soft-texture based on physicochemical properties including amylose content (AC), amylopectin content (AP), gelatinization temperature (GT), and gel consistency (GC) (Juliano and Perez 1984; Lanceras et al. 2000; Hsu et al. 2014). QTL mapping of the cooking quality of KDML105 was reported (Lanceras et al. 2000) in a 141 F8 recombinant inbred line (RIL) population from a cross between KDML105 and CT9993-5-10-1-M, a drought tolerant, japonica, upland rice from the Center of International Tropical Agriculture (CIAT). The major QTL on chromosome 6, known as the Waxy locus, with modifier genes on chromosomes 3, 4, and 7, determined 14-16\% AC of KDML105. AC and GC were linked on QTLch6. The waxy allele of KDML105 was classified as $W x^{b}$ or $W x^{g 1}$ (Lanceras et al. 2000; Teng et al. 2012). Three QTLs for GT were mapped on chromosome 6 as the single major QTL, and the two minor QTLs were mapped on chromosome 2. The major QTLch6 for GT is known as the alk locus encoding soluble starch synthase IIa (SSIIa) (Umemoto et al. 2002). Grain aroma is controlled by a single recessive gene located on chromosome 8 (Singh et al. 2007; Tragoonrung et al. 1996). QTL analysis of grain aroma identified one major QTL controlling grain aroma mapped close to RG28 on chromosome 8 (Ahn et al. 1992) in Azucena (Lorieux et al. 1996), Basmati (Singh et al. 2007) and KDML rice (Tragoonrung et al. 1996). Because sensory evaluation of grain aroma is inaccurate, the discovery of genes responsible for grain aroma for MAS is the key to improving KDML105.

\section{Discovery of the aromatic gene}

The content of 2-acetyl-1-pyrroline (2AP) is the major determinant of grain aroma, as the 2AP content and the QTL of grain aroma were coincidentally mapped on the same locus on chromosome 8 (Lorieux et al. 1996). Map-based cloning of the aromatic genes in KDML105 was initiated on Os $2 A P$ isogenic lines differing in $2 \mathrm{AP}$ content and developed from a KDML cross (Vanavichit et al. 2004; Vanavichit et al. 2005). The responsible gene, named $O s 2 A P$, was identified as a member of gammaaminobutylaldehyde dehydrogenase $(A M A D H)$ and functions as the metabolic switch between $\gamma$ aminobutylaldehyde (GBAL) and gamma-aminobutyric acid (GABA) in non-aromatic isogenic lines (Vanavichit et al. 2005). The crystallization of the 503-amino acid Os $2 A P$ protein from the non-aromatic isogenic line was reported (Kuaprasert et al. 2011). The structure was predicted to contain three binding domains: an NAD+ binding, an oligomerization, and a substrate binding domain where an aldehyde dehydrogenase cysteine subdomain was located (Chen et al. 2008; Wongpanya et al. 2011). In the aromatic isogenic lines and KDML105, the specific 8-bp deletion was identified within exon 7 of the $A M A D H$ of KDML105, causing a premature stop codon, non-sense-mediated decay, and non-functioning of Os $2 A P$, respectively (Vanavichit et al. 2005). RNAi against the Os2AP in the non-aromatic Japonica rice cv. Nipponbare resulted in the suppression of $A M A D H$ expression, resulting in the accumulation of $2 \mathrm{AP}$ at the level of KDML105 under the same growing condition (Vanavichit et al. 2005). Similar conclusions for the gene responsible for emerging aromatic rice and its aromatic compound biosynthesis switch were reported by most of the research groups as $B A D H 2$ (Bradbury et al. 2005; Chen et al. 2008; Sun et al. 2008; Shi et al. 2008; Bradbury et al. 2008). Comparing the aromatic isogenic line and RNAi in the $\mathrm{N}^{15}$ dilution experiment and inclusion of the inhibitors of enzymes in polyamine biosynthesis revealed ornithine as the initial amino acid precursor of $\mathrm{N}$, and polyamine is a major biosynthetic pathway leading to 2AP accumulation (Vanavichit et al. 2005; Vanavichit and Yoshihashi 2010).

\section{Variation in aromatic quality}

Among major aromatic rice cultivars, although they carry the same aromatic allele of $A M A D H$, considerable variation in 2AP content was reported, for example, in Basmati rice $(0.34 \mathrm{ppm})$, Jasmine rice $(0.81 \mathrm{ppm})$ and Texmati rice (0.53 ppm) (Goufo et al. 2010; Gaur et al. 2016). Environmental factors will always have a strong influence on the synthesis and degradation of 2AP 
content, resulting in quantitative variation of $2 \mathrm{AP}$ in rice grains. Additionally, other volatile compounds may add flavors to the pandan-like aroma. Analysis of volatile aromatic compounds during grain ripening identified odor-active compounds (OAC), including 2AP, decanal, pentanal, phenylacetaldehyde, hexanal, (E)-2-nonenal, nonanal, heptanal, 1-octanol, 1-octen-3-ol, and 2pentylfuran as contributors toward the unique sensory of specific rice fragrance (Hinge et al. 2016). Also, terpenoids, another class of volatile aromatic compounds found mostly in herbs, were identified in rice bran from purple, red, and brown rice varieties (Chumpolsri et al. 2015). Also, in the rice bran extracts of KDML105, major terpenoid odorants were found, such as limonene, trans-b-ocimene, b-cymene, and linalool (Chumpolsri et al. 2015). This finding may help explain the difference in the sensory evaluation of several aromatic rice varieties before and after cooking.

\section{Geographical dependency}

The accumulation of $2 \mathrm{AP}$ and grain qualities of aromatic, low-amylose rice is influenced by season and production area. The first report came from seven KDML rice samples collected between 2000 and 2001 from the north $(\mathrm{N})$, central $(\mathrm{C})$, and northeast (NE) regions of Thailand, which were quantified for grain 2AP content (Yoshihashi et al. 2004). The outcomes showed that the lowland rainfed area in the NE was the optimal environment for the accumulation of 2AP in rice grain (Yoshihashi et al. 2004). In particular, the NE had the best rice quality regarding physical appearance and cooking qualities (Anun et al. 2000). Environmental variation of cultivated areas affects the nitrogen, lipid, starch, fiber, and ash of polished rice (McCall et al. 1953), and low-amylose rice was particularly sensitive (Asaoka et al. 1989). Based on physical and cooking quality evaluation, the production area of KDML105 was classified as most favorable, favorable, or less favorable (Anun et al. 2000). Based on pasting properties rapid visco analysis (RVA) and the colorimetric properties of rice starch (Differential Scanning Colorimetry analysis), KDML105 environmental quality was classified into five groups: most favorable (one group), favorable (one group), and less favorable (three sub-groups) (Pitiphunpong and Suwannaporn 2009). In the most favorable area, "Tung-kula-rong-hai," which comprises three provinces in central NE Thailand, was praised for the geographical distinction for overall Jasmine rice qualities, in particular, 2AP (Yoshihashi et al. 2004). Poor fertility, sandy and mildly saline soil, and a cool, dry, sunny atmosphere during the ripening stage are distinctive characteristics of the area that affect both grain quality and grain 2AP content (Yoshihashi et al. 2004).

\section{Susceptibility to biotic stresses}

KDML105 and its induced-mutation RD15 and RD6, are highly susceptible to bacterial leaf blight (BLB), leaf/neck blast and brown planthopper/whiteback hopper because of the lack of $R$ genes (Toojinda et al. 2005). Overall, the $3.2 \mathrm{M}$ ha production area for KDML105 and RD15 is considered the largest single varietal type in a lowland rainfed ecosystem and is at high risk of the BLB, BL, and $\mathrm{BPH}$ outbreak. In lowland rainfed conditions, blast disease caused by Pyricularia grisea has threatened KDML, RD15, and RD6 productivity at every stage of growth, but particularly during the ripening stage, called neck blast. Of all rice growing countries, Thailand has the most diversified pathotypes in the world (Sreewongchai 2008; Chaipanya et al. 2017), as the fungus mutates quickly. In October 1993, 200,000 ha of Jasmine rice was devastated during the ripening stage, when farmers have no option for mitigation (Rice Today January-March 2006). Breeding for durable blast resistance from various donors with conventional and marker-assisted selection has reduced farmers' risk of devastation by disease and ensured the grain yield and quality of Thai Jasmine Rice. Lacking major R genes, KDML and RD15 are highly susceptible to BPH (Nilaparvata lugens Stål) in every stage of plant development (Jairin et al. 2005). Also, releasing aromatic compound 2AP from all plant parts making KDML even more risk of being devastated as 2AP may act as a possible chemical attractant to brown planthopper (BPH) (Kamolsukyunyong et al. 2013). Therefore, breeding for durable resistance to $\mathrm{BLB}, \mathrm{BL}$, and $\mathrm{BPH}$ of KDML is the most practical mitigation strategy to prevent crop loss.

\section{New generation of jasmine Rice: Plus one}

At the initial stage, mutation breeding utilizing gamma rays generated two important progenies: RD6, waxy Jasmine rice, and RD15, early-maturing Jasmine rice, which were released in 1977 and 1978, respectively (Rice Department). The first blast tolerant variety with a Jasmine-like quality was initiated in 1999 using IR77924-62-71-1-2 as the donor for two backcrosses to KDML, followed by pedigree selection (Supapoj et al. 2009). The elite progeny RD33, photoperiod-insensitive Jasmine rice, was released in 2006, as an alternative aromatic variety with blast resistance for $\mathrm{NE}$ and $\mathrm{N}$ Thailand (Rice Today Jan-March 2006). Marker-assisted backcrossing was comprehensively developed to add more resistance genes for diseases, insects, and abiotic stresses to KDML105 (Toojinda et al. 2005). These new generations of KDML progeny possess new traits, such as tolerance to submergence, bacterial leaf blight, and brown planthopper (Table 1). Background selection was performed using 65 well-distributed SSR markers to preserve most of the 
Table 1 KASP SNP markers for specific gene target used for MABC for improving KDML105

\begin{tabular}{|c|c|c|c|c|}
\hline Traits & Marker Name & Chr. & QTL/gene & LGC code ${ }^{f}$ \\
\hline Aroma & Aroma_2-3 & 8 & OsBADH2 & $002-0829.1$ \\
\hline Amylose content (AC) & wx_5UTR_G/T $T^{\mathrm{a}}$ & 6 & GBSS & $002-0052.1$ \\
\hline Gelatinization temperature (GT) & ALK_ex8_SNP_GC/TT ${ }^{\mathrm{a}}$ & 6 & sSIlla & 002-0049.1 \\
\hline Bacterial leaf blight (BLB) & $x a 5^{a}$ & 5 & $x a 5$ & 002-0775.1 \\
\hline Bacterial leaf blight (BLB) & SNP_P100 Xa21 ${ }^{\mathrm{e}}$ & 11 & $x a 21$ & 002-0998.1 \\
\hline Brown planthopper (BPH) & OsSTPS2_21bp_del ${ }^{b}$ & 4 & OsSTPS2 & 002-0120.1 \\
\hline Brown planthopper (BPH) & OsLecRK3_QBPHR ${ }^{\mathrm{e}}$ & 4 & OsLecRK3 & $002-0263.1$ \\
\hline Brown planthopper (BPH) & Bph32_2_1223332 & 6 & BPH 32 & \\
\hline Blast (BL) & BLch11-Pikm-2 ${ }^{c, d}$ & 11 & NB-ARC domain containing protein & 002-0754.1 \\
\hline Blast (BL) & TBGI055578_TC_Chr1 ${ }^{a}$ & 1 & secretory carrier-associated membrane protein & 002-0768.1 \\
\hline Blast (BL) & TBGI055841 ${ }^{\mathrm{a}}$ & 1 & hypothetical protein & $002-0819.1$ \\
\hline Blast (BL) & TBGI453126 & 11 & NBS-LRR disease resistance protein & 002-0820.1 \\
\hline Blast (BL) & TBGI453598 ${ }^{\mathrm{a}}$ & 11 & retrotransposon protein & 002-0821.1 \\
\hline Blast (BL) & TBGI454069 & 11 & receptor kinase-like protein & 002-0822.1 \\
\hline Blast (BL) & TBGI454717 & 11 & $\mathrm{C} 2 \mathrm{H} 2$ zinc finger protein & $002-0823.1$ \\
\hline Blast (BL) & TBGI454800 & 11 & zinc finger, C3HC4 type & $002-0824.1$ \\
\hline Submergence (SUB) & Sub1A_SNP1 ${ }^{e}$ & 9 & Subla & $002-0152.1$ \\
\hline Submergence (SUB) & Sub1C_loci5 $5^{\mathrm{a}}$ & 9 & Subic & 002-0995.1 \\
\hline
\end{tabular}

${ }^{a}$ Ruengphayak et al.; 2015

b Kamolsukyunyong et al.; 2013

c Chaipanya et al. 2017

d Ashikawa et al.; 2012

eUupublished

${ }^{f}$ LGCgroup, 2015

KDML105 genetic background for the adaptability and market quality of the Thai Jasmine rice (Table 2).

\section{KDML-Sub1}

The first marker-assisted selection line generated, HM80, was the first Sub1- Jasmine rice with flash flooding tolerance using IR49830-7-1-2-2 as the donor (Siangliw et al. 2003). This line was officially released in 2013 by the Rice Department. After the worst flooding in decades that affected Thailand in 2011, RD51 (HM80) was released for farmers in 2013. The planting area of the RD51 in 201314 was only 3000 ha in a flood-prone area or only $1 \%$ of the Thai Jasmine rice (KDML105 + RD15) (Table 3). Later, the HM80 was used as the general flooding donor to develop advance backcross pyramid lines (Fig. 2, Table 4).

\section{KDML-Xa21}

The introduction of the Xa21 gene from the highly resistant donor line, IR1188, into KDML105 successfully generated the first Jasmine-like BLB resistant line, HM812 (Fig. 2, Table 4). Because of the limitations of Xa21 against multiple strains of Xanthomonas oryzae (Xo) found in Thailand, xa5, xa33 (t), xa34(t), and qBB11 were introduced into the KDML105 background by MABC (Korinsak, 2009).

\section{KDML-BphQTLCh12}

More than $30 \mathrm{BPH} \mathrm{R}$ genes/quantitative trait loci (QTL) were mapped (Ling and Weilin 2016). Eight BPH R genes have been identified, including BPH14 (Du et al. 2009), BPH26 (Tamura et al. 2014), BPH3 (Liu et al. 2014), BPH29 (Wang et al. 2015), BPH9 (Zhao et al. 2016), BPH18 (Ji et al. 2016), BPH32 (Ren et al. 2016), and BPH31 (Prahalada et al. 2017). After the rigorous screening of the rice germplasm, two broadspectrum resistant donors for $\mathrm{BPH}$ were identified. Abhaya (Aba), a gall midge-resistant variety from India (Kalode et al. 1993; Rao and Kandalkar 1992), and Rathu Heenati (RHt), a broad-spectrum BPH-resistant variety from Sri Lanka (Lakshminarayana and Khush 1977), were used as donors in $\mathrm{MABC}$ to introduce durable $\mathrm{BPH}$ resistance into KDML. At the initial phase, the MABC program successfully introduced the BphQTLCh12 donated from Abhaya into HM811 (Table 4).

\section{New generation of jasmine Rice: Plus-two and plus-three}

Based on HM80 (Sub1) and HM811 (BPHch12), the major QTL for flooding tolerance, Sub1, was pyramided into HM811 using MABC with extreme phenotypic selection (Korinsak et al. 2016). The first pyramid line, 
Table 2 Pyramiding nine target genes/QTLs into the KDML105 background by marker-assisted backcrossing illustrated in Fig. 2. Background selection with markers was conducted only in the Plus-1 and Plus-4 BILs. X= The gene/QTLs were added to the new varieties by backcrossing

\begin{tabular}{|c|c|c|c|c|c|c|c|c|c|c|}
\hline & \multicolumn{9}{|c|}{ Gene/QTL } & \multirow{3}{*}{ Background Select } \\
\hline & \multirow{2}{*}{$\begin{array}{l}\text { Flooding } \\
\text { Sub1A }\end{array}$} & \multicolumn{2}{|c|}{ Bacterial leaf blight } & \multicolumn{3}{|c|}{ Brown planthopper } & \multirow[b]{2}{*}{ TPS } & \multicolumn{2}{|c|}{$\underline{\text { Neck/leaf blast }}$} & \\
\hline & & $X a 21$ & $x a 5$ & Bph $Q 12$ & Bph32 & Bph3 & & $B L Q 1$ & BLQ11 & \\
\hline \multicolumn{11}{|l|}{ Plus-One } \\
\hline HM80 & & & & & & & & & & 69 SSR markers \\
\hline HM812 & & & & & & & & & & 65 SSR markers \\
\hline HM811 & & & & & & & & & & 36 SSR markers \\
\hline \multicolumn{11}{|l|}{ Plus-Two } \\
\hline HM822 & & & & & & & & & & $\begin{array}{l}\text { Phynotypic background } \\
\text { selection }\end{array}$ \\
\hline HM821 & & & & & & & & & & $\begin{array}{l}\text { Phenotypic Background } \\
\text { selection }\end{array}$ \\
\hline \multicolumn{11}{|l|}{ Plus-Three } \\
\hline HM833 & & & & & & & & & & $\begin{array}{l}\text { Phenotypic background } \\
\text { selection }\end{array}$ \\
\hline \multicolumn{11}{|l|}{ Plus-Four } \\
\hline $\mathrm{HM}+4$ & & & & & & & & & & Genotype-by Sequencing \\
\hline
\end{tabular}

TPS Terpene synthase (OsSTPS2)

HM821, gained Jasmine-like physical, fragrant and cooking qualities with enhanced submergence tolerance and BPH resistance (Fig. 2). The second Plus-2 line, HM822 (Sub1A and Xa21), was combined by backcrossing HM80 to HM812 (Xa21). Following the similar MABC platform, HM821 was backcrossed to HM822 to generate the Plus-three line, HM83, in 2007 (Fig. 2).

\section{New generation of jasmine Rice: Plus-four}

Significant improvements to HM84 from the HM83 generation included introduction of new $\mathrm{BPH}, \mathrm{BLB}$, and Blast (BL) resistance into the HM83 background.

Table 3 Planting area of the Thai Jasmine rice (KDML105 + RD15), KDML-derived varieties, RD6, RD51, RD33, and Pathumthani 1 (PT1), in the wet and dry seasons, 2013-14 (Unpublished Rice Department 2014)

\begin{tabular}{llll}
\hline Varieties & Area (ha) & & Total (ha) \\
\cline { 2 - 3 } & Wet season & Dry season & \\
\hline KDML105 & $3,870,560$ & 3630 & $3,874,190$ \\
RD15 & 238,470 & 1580 & 240,050 \\
RD6 & $1,407,250$ & 390 & $1,407,640$ \\
RD51 & 3170 & 290 & 3460 \\
RD33 & 110 & 2950 & 3060 \\
PTT1 & 8900 & 46,110 & 55,010 \\
Total (ha) & $5,528,460$ & 54,950 & $5,583,410$ \\
\hline
\end{tabular}

This was the first generation into which the two QTLs for resistance to leaf and neck blast were introgressed into the Plus-3 background. In total, nine foreground genes/QTLs were introgressed into four Plus-4 BILs (Tables 2 and 4).

\section{Integration of durable RHt-BPH}

HM811 was utilized in several pyramiding breeding experiments until the Abhaya-derived BphQTLch12 was no longer effective against the emerging biotypes of $\mathrm{BPH}$. To overcome such rapid evolution, a more durable, tolerant donor, Rathu Heenati (RHt), was used for MABC in the second phase. QTL mapping analysis of RHt revealed BphQTL chr4 (Sun et al. 2005) and BphQTLchr6 (Jairin et al. 2007), which are later referred to as Bph3 (Liu et al. 2014) and Bph32 (Ren et al. 2016), respectively. Introgression of the QTL from RHt, a high-amylose rice, into the soft, susceptible Jasmine rice background was a challenge because of the tight linkage between BphQTLch6 and the waxy gene (GBSS). The genetic distance between RM589 (BphQTLch6) and RM190 (Waxy) is $1.6 \mathrm{cM}$ (Jairin et al. 2007) or $383 \mathrm{~Kb}$ (Jairin et al. 2009). The first step to break the tight linkage between the two loci was to generate a large F2 population between KDML105 (waxy b, bphQTLch6) and RHt (Waxy A, BphQTLch6), followed by rigorous MAS for the (waxy b, BphQTLch6) haplotype (Jairin et al. 2007). The recombinants were backcrossed to KDML 


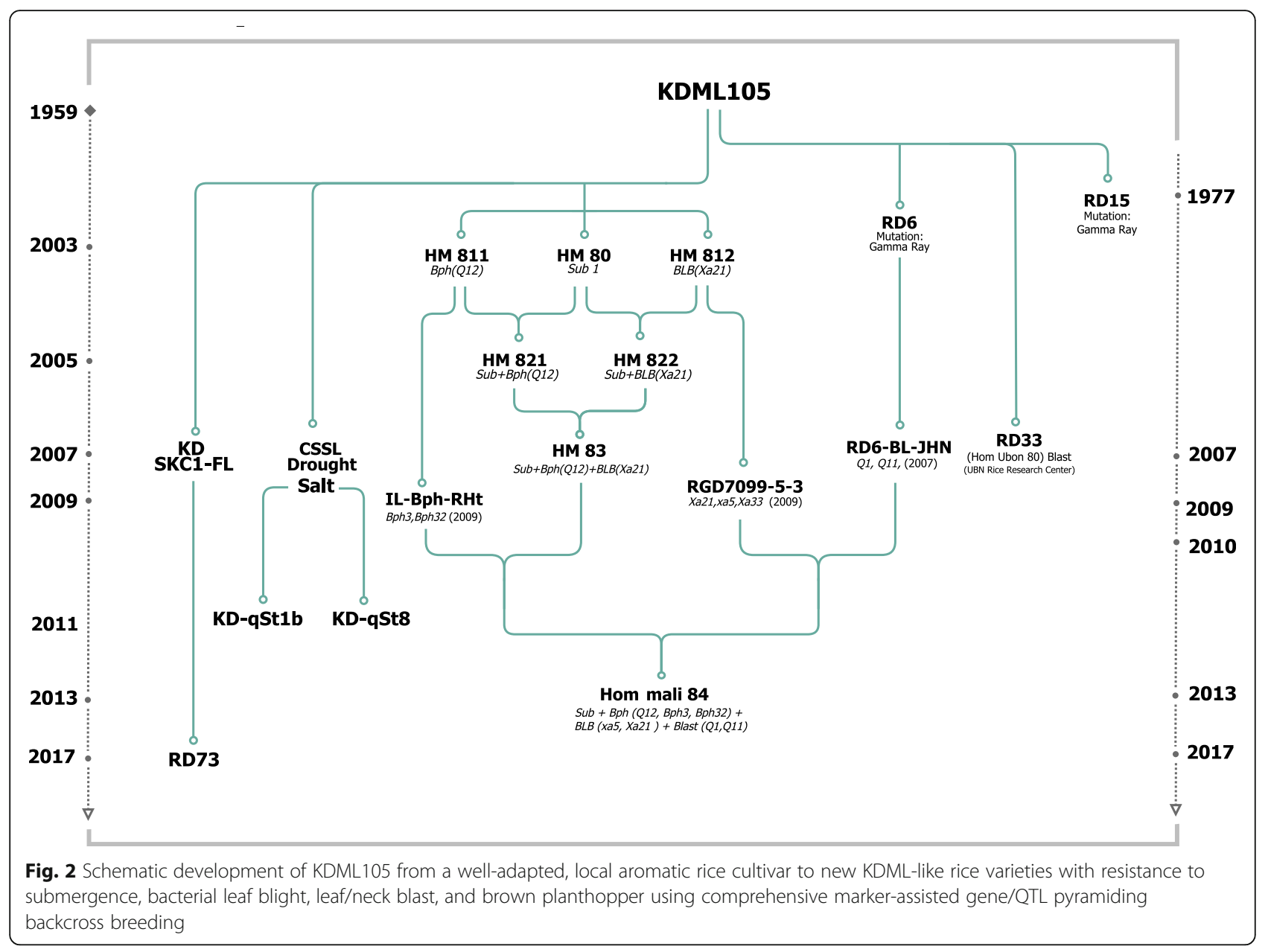

by MABC with $\mathrm{BPH}$ screening using a broad spectrum of Thai BPH biotypes (Jairin et al. 2007). For BphQTLch4, one resistant IL-BPH carried a functional sesquiterpene synthase (STPS) gene located on the long arm of chromosome 4. STPS was up-regulated by $\mathrm{BPH}$ infestation in the IL-BPH but with no expression in infested KDML, which carries a large mutation in its promoter region (Kamolsukyunyong et al. 2013). Analysis of monoterpenoid profiling released upon infestation from the IL-BPH and KDML revealed the differential accumulation of (E)-citral, citronellal, (E)-geraniol, $\beta$-citronellol, citronellyl acetate, and geranyl acetate in the $\mathrm{BPH}$ resistant IL (Pitija et al. 2014). Also, during BPH infestation, KDML105 activated the amino acid-mediated pathway, while IL-BPH-RHt activated nucleotide biosynthesis by the purine and pyrimidine compoundmediated salvage pathway (Uawisetwathana et al. 2015). Such targeted release of specific terpenoids and amino acids upon insect infestation formed the basis of antibiosis and antixenosis of the interaction between rice and $\mathrm{BPH}$.

\section{Broad-spectrum blast resistance}

Leaf and neck blast QTLs were genetically mapped using two recombinant inbred line (RIL) populations derived from KDML x JHN (Noenplab et al. 2006) and JHN x IR64 (Sreewongchai et al. 2010). The two broadspectrum resistant QTLs derived from JHN, BLQTLch1_ $J H N$ and BLQTLch11JHN, contributed 35-43\% percent variance explained (PVE) using three blast isolates. They were backcrossed using markers into RD6 (RD6-BLJHN) (Wongsaprom et al. 2010) and were used as the donor for HM83. Gene cloning of the two QTLs revealed Pish $J$ and Pi7J as BLQTLch1_JHN and BLQTLch11, respectively (Chaipanya et al. 2017). Four BLQTLs were combined into RD6 (RGD7005-164) (Noenplab et al. 2006; Wongsaprom et al. 2010; Sreewongchai et al. 2010; Korinsak 2010).

\section{Strengthening of BLB resistance}

With the rapid evolution of $X o$ pathotypes in recent years, screening of $\mathrm{R}$ genes for broad-spectrum resistance against the pathotypes in Thailand identified $x a 5$ and Xa33 as stronger $\mathrm{R}$ genes compared to Xa21 
Table 4 Trait evaluation, agronomic characteristics, grain quality, and cooking quality traits of the four selected HomMali 84, KDML105, and KD EDVs (For trait evaluation methods, see Additional file 1)

\begin{tabular}{|c|c|c|c|c|c|c|c|c|c|}
\hline \multirow[t]{2}{*}{ Name } & \multicolumn{4}{|c|}{ HM84 progenies } & \multirow[t]{2}{*}{ KDML105 } & \multicolumn{4}{|l|}{ KD EDV } \\
\hline & $\overline{6 \_14 G 08}$ & 24_16D06 & $2 \_14 \mathrm{~A} 03$ & 4_14B09 & & $\overline{\mathrm{KD}-\mathrm{BLB}}$ & Plus III & RD6-Blast & KD-Rathu \\
\hline${ }^{\mathrm{a} S u b}$ & 84.67 & 55.00 & 49.00 & 63.67 & 7.00 & 5.3 & 75.7 & 33.3 & 6.5 \\
\hline BLB(4 isolates) & $\mathrm{R}$ & $\mathrm{R}$ & $\mathrm{R}$ & $\mathrm{R}$ & $S$ & $\mathrm{R}$ & $\mathrm{R}$ & S & S \\
\hline BPH (2 biotype) & $\mathrm{R}$ & $\mathrm{R}$ & $\mathrm{R}$ & MR & $S$ & $\mathrm{~S}$ & MR & S & $\mathrm{R}$ \\
\hline Blast (8 Mixed) & $\mathrm{R}$ & $\mathrm{R}$ & $\mathrm{R}$ & $\mathrm{R}$ & $S$ & $S$ & $S$ & $\mathrm{R}$ & $S$ \\
\hline${ }^{\mathrm{b}} \mathrm{DM}$ & 126.67 & 125.33 & 129.00 & 120.33 & 120.67 & 120.33 & 122.00 & 121.67 & 127.30 \\
\hline NTP & 13.00 & 10.00 & 12.33 & 13.67 & 14.33 & 9.00 & 13.67 & 8.33 & 12.67 \\
\hline $\mathrm{PH}(\mathrm{cm})$ & 112.80 & 114.77 & 112.10 & 113.97 & 98.23 & 101.33 & 113.33 & 110.23 & 99.77 \\
\hline PSF(\%) & 72.33 & 72.27 & 71.07 & 68.57 & 68.10 & 60.27 & 77.27 & 55.07 & 74.33 \\
\hline TGW(g) & 30.03 & 29.93 & 27.80 & 27.90 & 29.93 & 29.65 & 28.89 & 26.33 & 27.97 \\
\hline GY(kg/ha) & 2766.69 & 2887.50 & 2266.69 & 2833.31 & 2554.19 & 2360.44 & 3130.31 & 2795.81 & 2921.06 \\
\hline cBR1/ (\%) & 76.06 & 73.39 & 68.10 & 73.03 & 70.40 & 70.64 & 69.48 & 72.54 & 71.88 \\
\hline HR1/ (\%) & 62.08 & 61.26 & 55.02 & 49.00 & 57.84 & 50.44 & 51.49 & 58.14 & 58.85 \\
\hline GL/W1/ & 3.4 & 3.16 & 3.2 & 3.29 & 3.42 & 3.24 & 3.22 & 3.11 & 3.15 \\
\hline PRL1/ (cm) & 0.75 & 0.73 & 0.75 & 0.78 & 0.72 & 0.7 & 0.71 & 0.7 & 0.67 \\
\hline ASV1/ & 6.0 & 6.1 & 6.0 & 6.0 & 6.0 & 2.3 & 6 & 6.1 & 6.2 \\
\hline Amylose(\%) & 16.42 & 17.7 & 14.14 & 14.55 & 17 & 16.58 & 17.21 & 8.2 & 16.94 \\
\hline
\end{tabular}

a/Trait evaluation

Sub $=$ Average $\%$ plant survival (\%PS) after 15 days of flash flooding

$\mathrm{BLB}=$ average lesion length in centimeters of the damage caused by the BB isolate including TXO152, TXO85, TXO155 and TXO156

$\mathrm{BPH}=$ Severity scores with UBN biotype at 9 DAI when TN1, the susceptible control died

Blast $=$ Average blast injury score when attacked by 8 mixed blast isolates from Thailand

b/Agronomic characteristics

DM (days to maturity), NTP (number of tillers per plant), PH (plant height from the soil surface to the neck of the panicle), PSF (percent spikelet fertility), TGW

(1000-grain weight) and GY (grain yield)

C/Grain quality and cooking quality

BR (brown rice), HR (head rice), GL/W (grain length-width ratio), PRL (polished rice length), AC (amylose content; Julaino, 1971), ASV (alkaline spreading value)

$\mathrm{EDV}=$ Essentially-derived variety

(Korinsak 2009). By using five effective Xo isolates, pyramided backcross inbred lines (BIL) with the combination of $x a 5, X a 21, x a 33(\mathrm{t}), X a 34(\mathrm{t})$, and $q B B 11$ on an indica variety were more effective than BIL with single $\mathrm{R}$ genes. Among single $\mathrm{R}$ genes, $x a 5$ showed the broadest resistance followed by Xa34 $(\mathrm{t})>x a 33(\mathrm{t}),>X a 21$ (Korinsak 2009). The addition of $x a 5$ to HM83 significantly improved resistance to BLB in the lowland rainfed and irrigated areas of Thailand. Therefore, deploying the best combination of $\mathrm{R}$ genes may prolong the productivity of newly-developed BLB resistant KDML105 in irrigated area.

\section{Successful pyramiding}

HM84, the outcome of genetic integration of the three KDML plus-one lines, delivered stronger BPH, BLB, and BL resistance into HM83 (Fig. 2 and Table 4). Nine foreground genes/QTLs were incorporated by MABC into KDML105 in a stepwise approach, from Plus-1, Plus-2, Plus-3, and Plus-4 (Table 2). Four sub-lines of HM84 derived after background selection showed tolerance to submergence, BPH, BLB, and BL, while good cooking quality and aroma were maintained (Table 4). Under pest-free conditions, HM84 on average yielded almost equal to KDML105 (Table 4). Under flooding, BLB, BL, and $\mathrm{BPH}$ epidemics, HM84 showed clear advantages over the susceptible KDML105 due to the addition of resistance genes/QTLs (data not shown).

\section{KDML-CSSL as a platform for improving drought tolerance}

The limitation of map-based cloning of QTL had been the driving factor in the development of KDML105 chromosome segment substitution lines (CSSLs). The process of map-based cloning requires the development of near-isogenic lines for fine-scale mapping followed by QTL cloning. CSSL is a novel mapping population that carries a specific chromosomal segment from a donor line in the genetic background of the recurrent line. Association of QTL with a particular chromosomal segment can be performed by genetic analysis using a CSSL population; at the same time, CSSLs can be developed quickly as NIL-containing target regions/QTLs of interest. This is a good strategy to accurately study genetic regions for complex traits such as drought resistance. 
A population of chromosomal segment substitution lines with a KDML105 background was developed by crossing KDML105 with IR68586-F2-CA-31 (also known as DH103) and IR68586-F2-CA-143 (DH212), which are doubled haploid lines derived from a cross between CT9993-510-1-M (CT9993), an upland japonica rice, and IR62266-42-6-2 (IR62266), an irrigated indica rice (Toojinda et al. 2011). The QTL segment in the CSSLs was originally mapped from the doubled haploid population of CT9993 and IR62266. These populations differ in potential yield, osmotic adjustment (OA), and root characteristics such as a deep, thick rooting system. This population was developed at CIAT, Colombia, and the IRRI, Philippines. Several research institutes have collaborated and used this population for the genetic study of traits associated with drought tolerance (Blum et al. 1999; Tripathy et al. 2000; Zhang et al. 2001; Babu et al. 2003; Robin et al. 2003; Nguyen et al. 2004).

The QTL study was conducted by phenotyping the $220 \mathrm{DH}$ lines and parents with yield, yield components and agronomic traits under control and drought conditions. A population of $154 \mathrm{DH}$ lines was randomly selected from the full set used in developing the genetic map (Zhang et al. 2001), which was used to identify the QTL-controlling traits above. Five chromosomal segments, namely, chromosomes 1, 3, 4, 8 and 9, were identified carrying several overlapping QTL for drought resistance traits covering 49, 15, 53, 60 and $30 \mathrm{cM}$ of the chromosomes, respectively (Lanceras et al. 2004). These regions were introgressed into KDML105 by MABC and selfing until $\mathrm{BC}_{3} \mathrm{~F}_{3}$, and lines carrying the QTL segments were selected using SSR markers in every generation (Siangliw et al. 2007). Further backcrossing was advanced into $\mathrm{BC}_{5}$, and purification for homozygosity at the QTL regions was accomplished in the $F_{2}, F_{3}$, and $F_{4}$ generations. In total, 135 KDML105 CSSLs were developed, comprised of 30, 22, 41, 31 and 15 lines carrying QTL in chromosomes 1, 3, 4, 8 and 9, respectively (Toojinda et al. 2011; Kanjoo 2012). These isoQTL lines can be used to develop KDML Plus-5 for greater drought tolerance shortly.

\section{Adapting KDML to high-saline soil}

The SKC1 gene on chromosome 1, an HKT-type transporter $(O s H K T 1 ; 5)$, was identified as a controller of shoot $\mathrm{K}$ content related to salinity tolerance in rice (Gregorio et al. 2002, Lin et al. 2004; Ren et al. 2005; Thomson et al. 2010). Introgression of SKC1 from FL496 (IR66946-3R-196-1-1) or FL530 (IR66496-3R230-1-1) into KDML105 was accomplished using MABC to generate KD-SKC1-FL (Fig. 2). The improved KDSKC1-FL showed greater tolerance, with a lower $\mathrm{Na} / \mathrm{K}$ ratio and higher yield under salt stress at 10-12 $\mathrm{ds} \mathrm{m}^{-1}$ (Punyawaew et al. 2016). One elite line was released to farmers under the name "RD73" by the Thailand Rice Department in 2017. In addition to SKC1, qSt1b, located on the lower region of chromosome 1, significantly improved photosynthesis efficiency with less injury under salinity stress (Siangliw et al. 2014; Kanjoo et al. 2011; Thomson et al. 2010; Chutimanukul et al. 2013). The third QTL, qSt8, identified on chromosome 8, protected rice plants from salinity stress. KD-CSSLqST1/8 carrying qSt1b and qSt8 shows more tolerance under salt stress at 10-14 dS m ${ }^{-1}$ (Kanjoo et al. 2011, Chutimanukul et al. 2013, Nounjan et al. 2016). Therefore, pyramiding of SKC1, qSt1, and qSt8 may enhance productivity under salt stress.

\section{Conclusions}

The 58 years-old KDML105, selected from a widely adapted aromatic landrace found in the lowland rainfed area, has become an iconic rice cultivar since 1959. To continue its productivity into the next century, KDML was rigorously and carefully enriched for new traits using mutation, conventional breeding, and MABC while conserving its superb cooking quality and adaptive advantages in the lowland rainfed area. After 13 years of MABC, new generations of KDML backcross inbred lines were carefully developed by pyramiding six QTLs with six gene-specific alleles into KDML105. Salt tolerance KDML Plus-1 and Drought tolerance CSSLs are integrating into the HM84. This newly emerging HM84 will have advantages over KDML105 in that affected area where bacterial leaf blight, blast, brown planthopper, and flooding are problems. With these adaptive advantages and superb cooking quality, the innovative KDML 105 will be more productive in the subsistence and pesticidefree lowland rainfed area.

\section{Additional file}

Additional file 1: Evaluation of abiotic and biotic stress traits and recording of important agronomic traits method. (DOCX $22 \mathrm{~kb}$ )

\footnotetext{
Abbreviations

2AP: 2-acetyl-1-pyrroline; AC: amylose content; AP: amylopectin content BL: blast; BLB: bacterial leaf blight; BPH: brown planthopper; C: Central; CSSLs: chromosome segment substitution lines; EDV: Essentially-derived variety; GC: gel consistency; GT: gelatinization temperature; HM: Hom Mali; KDML105: Khao Dawk Mali 105; MABC: marker-assisted backcross selection; N: North; NE: North-East; PVE: percent variance explained; RHt: Rathu Heenati; RIL: recombinant inbred line; RVA: rapid visco analysis; Xo: Xanthomonas oryzae
}

\section{Acknowledgements}

This work was supported by the National Center for Genetic Engineering and Biotechnology (BIOTEC) and National Science and Technology

Development Agency (NSTDA), NSTDA Research Chair (Grant No. P12-01898), Agriculture Research Development Agency (ARDA) (Grant No. P12/2552), Rice Department and Kasetsart University. 


\section{Funding}

National Center for Genetic Engineering and Biotechnology (BIOTEC) and National. Science and Technology Development Agency (NSTDA)(NSTDA Research Chair (Grant No. P12-01898)). Agriculture Research Development Agency (ARDA) (Grant No. P12/2552).

\section{Availability of data and materials \\ Not applicable}

\section{Authors' contributions}

Conceived and writer: AP. Review BPH: WK. Review BLB, BL and MABC: SR and EP. Review drought and salinity: JLS and MS. Field data collection: SUT. Performed bioinformatics and statistical analysis: CS and EC. MABC design: TT. Review KDML history and statistics: SOT. All authors read and approved the final manuscript.

\section{Ethics approval and consent to participate}

Not applicable

\section{Consent for publication}

Not applicable

\section{Competing interests}

The authors declare that they have no competing interests.

\section{Publisher's Note}

Springer Nature remains neutral with regard to jurisdictional claims in published maps and institutional affiliations.

\section{Author details}

'Rice Science Center, Kasetsart University, Kamphaeng Saen, Nakhon Pathom 73140, Thailand. ${ }^{2}$ Agronomy Department, Faculty of Agriculture at Kamphaeng Saen, Kasetsart University, Kamphaeng Saen, Nakhon Pathom 73140, Thailand. ${ }^{3}$ Rice Gene Discovery Laboratory, National Center for Genetic Engineering and Biotechnology (BIOTEC), National Science and Technology Development Agency (NSTDA), Kasetsart University, Kamphaeng Saen, Nakhon Pathom 73140, Thailand. ${ }^{4}$ Bureau of Rice Research and Development (Rice Department), 50 Paholyothin Rd, Chatuchak, Bangkok 10900, Thailand. ${ }^{5}$ Plant Biotechnology Research Unit, National Center for Genetic Engineering and Biotechnology (BIOTEC), National Science and Technology Development Agency (NSTDA), 113 Thailand Science Park, 113 Thailand Science Park, Khlong Luang, Pathum Thani 12120, Thailand. ${ }^{6}$ National Center for Genetic Engineering and Biotechnology (BIOTEC), National Science and Technology Development Agency (NSTDA), 113 Thailand Science Park, 113 Thailand Science Park, Khlong Luang, Pathum Thani 12120, Thailand.

\section{Received: 2 November 2017 Accepted: 20 March 2018}

\section{Published online: 09 April 2018}

\section{References}

Ahn SN, Bollich CN, Tanksley SD (1992) RFLP tagging of a gene for aroma in rice. Theor Appl Genet 84:825-828

Anun D, Suthep L, Boriboon S, Vassana V, Ngamchuen K (2000) Characterization of Khao Dawk Mali 105 and RD15 rice cultivated area in Thailand. In: Research of Rice and Rice products research program, Department of Agriculture, Bangkok

Arunin S (1984) Characteristics and management of salt-affected soil in the northeast of Thailand. In: Ecology and management of problem soils in Asia. Food and Fertilizer Technology Center for the Asian and Pacific Region, Taipei, Rep. of China

Arunin S, Pongwichian P (2015) Salt-affected soils and management in Thailand. Bull Soc Sea Water Sci Jpn 69(5):319-325

Asaoka M, Okuno K, Hara K, Oba M, Fuwa H (1989) Effects of environmental temperature at the early developmental stage of seeds on the characteristics of endosperm starches of rice (Oryza sativa L.) Denpun Kagaku 36:1-8

Ashikawa I, Hayashi N, Abe F, Wu J, Matsumoto T (2012) Characterization of the rice blast resistance gene Pik cloned from Kanto 51. Mol Breed 30:485-494

Babu RC, Nguyen BD, Chamarerk V, Shanmugasundaram P, Chezhian P, Jeyaprakash P, Ganesh SK, Palchamy A, Sadasivam S, Sarkarung S, Wade LJ, Nguyen HT (2003) Genetic analysis of drought resistance in rice by molecular markers: association between secondary traits and field performance. Crop Sci 43:1457-1469
Banco DM, Yamauchi A, Kamoshita A, Wade L, Pardales JR Jr (2000) Dry matter production and root system development of rice cultivars under fluctuating soil moisture. Plant Prod Sci 3(2):197-207

Blum A, Mayer J, Golan G, Sinmena B (1999) Drought tolerance of a doubledhaploid line population if rice in the field. In: Ito O, O'Toole J, Hardy B (eds) Genetic improvement of rice for water-limited environments. International Rice Research Institute, Los Banos, Philippines, pp 319-330

Bradbury LMT, Fitzgerald TL, Henry RJ, Jin Q, Waters DL (2005) The gene for fragrance in rice. Plant Biotechnol J 3:363-370

Bradbury LMT, Gillies SA, Brushett DJ, Waters DLE, Henry RJ (2008) Inactivation of an aminoaldehyde dehydrogenase is responsible for fragrance in rice. Plant Mol Biol 68:439-449

Bureau of Rice Research and Development (2010) Khao Dawk Mali 105. Rice Department, Bangkok. ISBN: 978-974-403-692-6

Chaipanya C, Jeanie M, Yanoria T, Quime B, Longya A, Korinsak SP, Korinsak S, Toojinda T, Vanavichit A, Jantasuriyara C, Zhou B (2017) Dissection of broadspectrum resistance of the Thai rice variety Jao Hom Nin conferred by two resistance genes against rice blast. Rice 10:18

Chen S, Yang Y, Shi W, Ji O, He F, Zhang Z, Cheng Z, Liu X, Xu M (2008) Badh2, encoding betaine aldehyde dehydrogenase, inhibits the biosynthesis of 2-acetyl-1-pyrroline, a major component in rice fragrance. Plant Cell 20:1850-1861

Chumpolsri W, Wijit N, Boontakham P, Nimmanpipug N, Sookwong P, Luangkamin S, Wongpornchai S (2015) Variation of terpenoid flavor odorants in the bran of some black and white rice varieties analyzed by GCXGC-MS. J Food Nutr Res 3(2):114-120

Chutimanukul P, Chaidee A, Buaboocha T, Siangliw M, Toojinda T, Chadchawan S, Kositsup B (2013) Effect of salt stress on photosynthesis and growth in salttolerant rice lines obtained from a CSSL population. Thai I Genet S 1:276-279

Department of Foreign Trade (2014) Rice in Thailand: Agriculture, history what makes jasmine rice so special. [cited 2017 Oct 18]. Available from: http:// factsanddetails.com/southeast-asia/Thailand/sub5_8h/entry-3321.html

Du B, Zhang W, Liu B, Hu J, Wei Z, Shi Z, He R, Zhu L, Chen R, Han B, He G (2009) Identification and characterization of Bph14, a gene conferring resistance to brown planthopper in rice. Proc Natl Acad Sci U S A 106:22163-22168

Gaur A, Shabir Wani H, Pandita D, Bharti N, Malav A, Shikari A, Bhat A (2016) Understanding the fragrance in rice. J Rice Res 4:e125

Goufo P. Duan M, Wongpornchai S, Tang X (2010) Some factors affecting the concentration of the aroma compound 2-acetyl-1-pyrroline in two fragrant rice cultivars grown in South China. Front Agric China 4:1-9

Gregorio GB, Senadhira D, Mendoza RD, Manigbas NL, Roxas JP, Guerta CQ (2002) Progress in breeding for salinity tolerance and associated abiotic stresses in rice. Field Crops Res 76:91-101

Hinge VR, Patil HB, Nadaf AB (2016) Aroma volatile analyses and 2AP characterization at various developmental stages in basmati and non-basmati scented rice (Oryza sativa L.) cultivars. Rice 9:38

Hsu YC, Tseng MC, Wu YP, Lin MY, Wei FJ, Hwu KK, Hsing YI, Lin YR (2014) Genetic factors responsible for eating and cooking qualities of rice grains in a recombinant inbred population of an inter-subspecific cross. Mol Breed 34:655-673

Im-Erb R, Neawsuparb K, Sombatpanit S (2013) Soil salinization assessment and monitoring at Boe Klue District, Nan Province, northern Thailand. In: Shahid S, Abdelfattah M, Taha F (eds) Developments in soil salinity assessment and reclamation. Springer, Dordrecht, pp 75-86

Jairin J, Phengrat K, Teangdeerith S, Vanavichit A, Toojinda T (2007) Mapping of a broad-spectrum brown planthopper resistance gene, Bph3, on rice chromosome 6. Mol Breed 19:35-44

Jairin J, Teangdeerith S, Leelagud P, Kothcharerk J, Sansen K, Yi M, Vanavichit A, Toojinda T (2009) Development of rice introgression lines with brown planthopper resistance and KDML105 grain quality characteristics through marker-assisted selection. Field Crops Res 110:263-271

Jairin J, Toojinda T, Tragoonrung S, Tayapat S, Vanavichit A (2005) Multiple genes determining brown planthopper (Nilaparvata lugens Stål) resistance in backcross introgressed lines of Thai jasmine rice 'KDML105'. ScienceAsia 31:129-135

Ji H, Kim S-R, Kim Y-H, Suh J-P, Park H-M, Sreenivasulu N, Misra G, Kim S-M, Hechanova S-L, Kim H, Lee G-S, Yoon U-H, Kim T-H, Lim H, Suh S-C, Yang J, An G, Jena KK (2016) Map-based cloning and characterization of the bph18 gene from wild rice conferring resistance to brown planthopper (bph) insect pest. Sci Rep 6:34376

Jongdee B, Pantuwan G, Fukai S, Fischer K (2006) Improving drought tolerance in rainfed lowland rice: an example from Thailand. Agric Water Manag 80:225-240 
Juliano BO, Perez CM (1984) Result of a collaborative test on the measurement of grain elongation of milled rice during cooking. J Cereal Sci 2:281-292

Kalode MB, Bentur JS, Prasada Rao U (1993) Rice cultures resistant to rice gall midge (GM) biotypes 1 and four under artificial infestation in the greenhouse. Int Rice Res Newsl 10(2):17-18

Kamolsukyunyong W, Sukhaket W, Ruanjaichon V, Toojinda T, Vanavichit A (2013) Single-feature polymorphism mapping of isogenic rice lines identify the influence of terpene synthase on brown planthopper feeding preferences. Rice 6:18

Kanjoo V (2012) Development of chromosome segment substitution lines related to drought tolerance in rice (Oryza sativa L.). Dissertation, Agricultural Biotechnology, Graduate School, Kasetsart University, p108

Kanjoo V, Jearakongman K, Punyawaew K, Siangliw JL, Siangliw M, Vanavichit A, Toojinda T (2011) Co-location of quantitative trait loci for drought and salinity tolerance in rice. Thai J Genet 4(2):126-138

Kano-Nakata M, Gowda VRP, Henry A, Serraj R, Inukai Y, Fujita D, Kobayashi N, Suralta RR, Yamauchi A (2013) Functional roles of the plasticity of root system development in biomass production and water uptake under rainfed lowland conditions. Field Crop Res 144:288-296

Korinsak S (2009) Marker-assisted pyramiding bacterial blight resistance genes $(x a 5, X a 21, x a 33(t), X a 34(t)$ and $q B B 11)$ in rice. Dissertation, Kasetsart University

Korinsak S, Siangliw M, Kotcharerk J, Jairin J, Siangliw JL, Jongdee B, Pantuwan G, Sidthiwong N, Toojinda T (2016) Improvement of the submergence tolerance and the brown planthopper resistance of the Thai jasmine rice cultivar KDML105 by pyramiding Sub1 and Qbph12. Field Crop Res 188:105-112

Korinsak SP (2010) Identification of blast resistance QTLs in two rice RIL populations and marker assisted selection for pyramiding of four QTLs in RD6 rice variety. Dissertation, Kasetsart University

Kuaprasert B, Silprasit K, Horata N, Khunrae P, Wongpanya R, Boonyalai N, Vanavichit A, Choowongkomon K (2011) Purification, crystallization and preliminary $X$-ray analysis of recombinant betaine aldehyde dehydrogenase 2 $(\mathrm{OsBADH2})$, a protein involved in jasmine aroma, from Thai fragrant rice (Oryza sativa L.) Acta Cryst 67:1221-1223

Kumboonreang $N$ (2011) Effect of light duration on panicle initiation and advantages of off-season growing KDML105 rice using short day period. Dissertation, Suranaree University of Technology

Lakshminarayana A, Khush GS (1977) New genes for resistance to the brown planthopper in rice. Crop Sci 17:96-100

Lanceras J, Huang ZL, Naivikul O, Vanavichit A, Ruanjaichon V, Tragoonrung S (2000) Mapping of genes for cooking and eating qualities in Thai jasmine rice (KDML105). DNA Res 7:93-101

Lanceras J, Pantuwan G, Jongdee B, Toojinda T (2004) Quantitative trait loci associated with drought tolerance at reproductive stage in rice. Plant Physiol 135:384-399

LGCgroup (2015) KASP genotyping technology. https://www.lgcgroup.com/ products/kasp-genotyping-chemistry/\#.Wrhk3dR94_4

Lin HX, Zhu MZ, Yano M, Gao JP, Liang ZW, Su WA, Hu XH, Ren ZH, Chao DY (2004) QTLs for $\mathrm{Na}+$ and $\mathrm{K}+$ uptake of the shoots and roots controlling rice salt tolerance. Theor Appl Genet 108:253-260

Ling Y, Weilin Z (2016) Genetic and biochemical mechanisms of rice resistance to planthopper. Plant Cell Rep 35:1559-1572

Liu Y, Wu H, Chen H, Liu Y, He J, Kang H, Sun Z, Pan G, Wang Q, Hu J, Zhou F, Zhou K, Zheng X, Ren Y, Chen L, Wang Y, Zhao Z, Lin Q, Wu F, Zhang X, Guo $X$, Cheng $X$, Jiang L, Wu C, Wang H, Wan J (2014) A gene cluster encoding lectin receptor kinases confers broad-spectrum and durable insect resistance in rice. Nat Biotechnol 33:301-305

Lorieux M, Petrov M, Huang N, Guiderdoni E, Ghesquière A (1996) Aroma in rice: genetic analysis of a quantitative trait. Theor Appl Genet 93:1145-1151

McCall ER, Jurgens JF, Hoffpauir CL, Pons WA, Stark SM, Cucullu AF, Heinzelman DC, Cirino VO, Murray MD (1953) Composition of rice: influence of variety and environment on physical and chemical composition. J Agric Food Chem 1:988-992

Nguyen TT, Klueva N, Chamareck V, Aarti A, Magpantay G, Millena AC, Pathan MS, Nguyen HT (2004) Saturation mapping of QTL regions and identification of putative candidate genes for drought tolerance in rice. Mol Gen Genomics 272:35-46

Noenplab A, Vanavichit A, Toojinda T, Sirithunya P, Tragoonrung S, Sriprakhon S, Wongsaprom C (2006) QTL mapping for leaf and neck blast resistance in Khao Dawk Mali 105 and Jao horn Nin recombinant inbred lines. ScienceAsia 32(2):133-142

Nounjan N, Siangliw JL, Toojinda T, Chadchawan S, Theerakulpisut P (2016) Saltresponsive mechanisms in chromosome segment substitution lines of rice (Oryza sativa L. cv. KDML105). Plant Physiol Biochem 103:96-105
O'Toole JC, Bland WL (1987) Genotypic variation in crop plant root systems. Adv Agron 41:91-145

Pitija K, Kamolsukyumyong W, Vanavichit A, Sookwong P, Mahatheeranont S (2014) Monoterpenoid allelochemicals in resistance rice varieties against brown planthoppers, Nilaparvatalugens (Stål). JOAAT 1(2):82-88

Pitiphunpong S, Suwannaporn P (2009) Physicochemical properties of KDML105 rice cultivar from different cultivated locations in Thailand. J Sci Food Agric 89:2186-2190

Prahalada GD, Shivakumar N, Lohithaswa HC, Sidde Gowda DK, Ramkumar G, Kim S-R et al (2017) Identification and fine mapping of a new gene, BPH31 conferring resistance to brown planthopper biotype 4 of India to improve rice, Oryza sativa L. Rice 10(1):41

Punyawaew K, Suriya-arunroj D, Siangliw M, Thida M, Lanceras-Siangliw J, Fukai S, Toojinda T (2016) Thai jasmine rice cultivar KDML105 carrying Saltol QTL exhibiting salinity tolerance at seedling stage. Mol Breed 36:150

Rao PSP, Kandalkar HG (1992) Identification of a new Asian rice gall midge (GM) population in Bhandara district Maharashtra, India, and highly resistant genotypes. Int Rice Res Notes 17:9-10

Ren J, Gao F, Wu X, Zeng L, Lv J, Su X, Luo H, Ren G (2016) BPH32, a novel gene encoding an unknown SCR domain-containing protein, confers resistance against the brown planthopper in rice. Sci Rep 6:37645

Ren ZH, Gao JP, Li LG, Cai XL, Huang W, Chao DY, Zhu MZ, Wang ZY, Luan S, Lin HX (2005) A rice quantitative trait locus for salt tolerance encodes a sodium transporter. Nat Genet 37:1141-1146

Rice Knowledge Bank, IRRI. Salinity. http://www.knowledgebank.irri.org/decisiontools/rice-doctor/rice-doctor-fact-sheets/item/salinity

Rice Today (2006) Improving the sacred. January-March, 2006. https://www. scribd.com/document/98480901/RT-Vol-5-No-1-All-in-the-genes

Robin S, Pathan MS, Courtois B, Lafitte R, Carandang S, Lanceras JL, Amante M, Nguyen HT, Li Z (2003) Mapping osmotic adjustment in an advanced backcross inbred population of rice. Theor Appl Genet 107:1288-1296

Ruengphayak S, Chaichumpoo E, Phromphan S, Kamolsukyunyong W, Sukhaket W, Phuvanartnarubal E, Korinsak S, Korinsak S, Vanavichit A (2015) Pseudobackcrossing design for rapidly pyramiding multiple traits into a preferential rice variety. Rice 8:7

Shi W, Yang Y, Chen S, Xu M (2008) Discovery of a new fragrance allele and the development of functional markers for the breeding of fragrant rice varieties. Mol Breed 22:185-192

Siangliw JL, Jongdee B, Pantuwan G, Toojinda T (2007) Developing KDML105 backcross introgression lines using marker-assisted selection for QTL associated with drought tolerance in rice. ScienceAsia 33:207-214

Siangliw M, Phatanathara A, Toojinda T, Theerakulpisut P, Fukai S, Vanavichit A (2014) QTL and candidate gene identification for salt tolerance and $\mathrm{Na} / \mathrm{K}$ ratio at seedling stage under modified soil and hydroponic conditions in rice (Oryza Sativa L.) In: The 4th international Rice congress (IRC2014), Bangkok, Thailand October 27 - November 1, 2014

Siangliw M, Toojinda T, Tragoonrung S, Vanavichit A (2003) Thai jasmine rice carrying QTLch9 is submergence tolerance. Ann Bot 91:255-261

Singh R, Singh RK, Sharma TR, Singh A, Singh NK (2007) Fine mapping of aroma QTLs in basmati rice (Oryza sativa $\mathrm{L}$ ) on chromosomes 3, 4 and 8. J Plant Biochem Biot 16:75-82

Sreewongchai T (2008) Identification of Magnaporthe grisea avirulence genes specific to rice blast resistance genes. Dissertation, Kasetsart University

Sreewongchai T, Toojinda T, Thanintorn N, Kosawang C, Vanavichit A, Tharreau D, Sirithunya P (2010) Development of elite indica rice lines with wide spectrum of resistance to Thai blast isolates by pyramiding multiple resistance QTLS. Plant Breed 129:176-180

Sun L, Su C, Wang C, Zhai H, Wan J (2005) Mapping of a major resistance gene to the brown planthopper in the rice cultivar Rathu Heenati. Breed Sci 55:391-396

Sun SH, Gao FY, Lu XJ, Wu XJ, Wang XD, Ren GJ, Luo H (2008) Genetic analysis and gene fine mapping of aroma in rice (Oryza sativa L, Cyperales, Poaceae). Genet Mol Biol 31:532-538

Supapoj N, Boonyawit C, Jongdee B, Varavat O, Chamarerk V, Phengrat J (2009) RD33 (Hawm Ubon 80) rice variety. Thai Rice Research J 3(2):20-38

Tamura Y, Hattori M, Yoshioka H, Yoshioka M, Takahashi A, Wu J, Sentoku N, Yasui $H$ (2014) Map-based cloning and characterization of a brown planthopper resistance gene BPH26 from Oryza sativa L. ssp. indica cultivar ADR52. Sci Rep 4:5872

Teng B, Zeng R, Wang Y, Liu Z, Zhang Z, Zhu H et al (2012) Detection of allelic variation at the $\mathrm{Wx}$ locus with single-segment substitution lines in rice (Oryza sativa L.) Mol Breed 30:583-595 
Thomson MJ, de Ocampo M, Egdane J, Rahman MA, Sajise AG, Adorada DL, Tumimbang-Raiz E, Blumwald E, Seraj ZI, Singh RK, Gregorio GB, Ismail AM (2010) Characterizing the Saltol quantitative trait locus for salinity tolerance in rice. Rice 3:148-160

Toojinda T, Siangliw JL, Punyawaew K, Kanjoo V (2011) Development of single QTL near-isogenic lines (NILs) of KDML105 for drought tolerance. In: Research rep. National Center for genetic engineering and biotechnology. NSTDA, Pathumthani, Thailand

Toojinda T, Tragoonrung S, Vanavichit A, Siangliw JL, Pa-In N, Jantaboon J, Siangliw M, Fukai S (2005) Molecular breeding for rainfed lowland rice in the Mekhong region. Plant Prod Sci 8:330-333

Tragoonrung S, Sheng JQ, Vanavichit A (1996) Tagging an aromatic gene in lowland rice using bulk segregant analysis. In: IRRI (eds) Rice Genetics III. Proc $3^{\text {rd }}$ Int. Rice Genet. Symp., Manila, Oct 16-20, 1995, pp 613-618

Tripathy JN, Zhang J, Robin S, Nguyen TT, Nguyen HT (2000) QTLs for cellmembrane stability mapped in rice (Oryza sativa L.) under drought stress. Theor Appl Genet 100:1197-1202

Uawisetwathana U, Graham S, Kamolsukyunyong W, Sukhaket W, Klanchui A, Toojinda T, Vanavichit A, Karoonuthaisiri N, Elliott C (2015) Quantitative 1H NMR metabolome profiling of Thai jasmine rice (Oryza sativa) reveals primary metabolic response during brown planthopper infestation. Metabolomics 11:1640-1655

Umemoto T, Yano M, Satoh H, Shomura A, Nakamura Y (2002) Mapping of a gene responsible for the difference in amylopectin structure between Japonica-type and indica-type rice varieties. Theor Appl Genet 104:1-8

USDA (2013) Bibliography on salt tolerance. Fibres, grains and special crops. Riverside, CA: Brown GE, Jr. Salinity Lab. US Department Agriculture, Agriculture Research Service

Vanavichit A, Kamolsukyurnyong W, Wanchana S, Wongpornchai S, Ruengphayak S, Toojinda T, Tragoonrung S (2004) Discovering genes for rice grain aroma. In: Proceedings the 1st international conference on Rice for the future, Kasetsart University, Bangkok, Thailand, 31 august - 3 September 2004

Vanavichit A, Yoshihashi T (2010) Molecular aspects of fragrance and aroma in rice. Adv Bot Res 56:49-73

Vanavichit A, Yoshihashi T, Wanchana S, Areekit S, Saengsraku D, Kamolsukyunyong W J Lanceras J, Toojinda T, Tragoonrung S (2005) Positional cloning of Os2AP, the aromatic gene controlling the biosynthetic switch of 2-acetyl-1-pyrroline and gamma-aminobutyric acid (GABA). In: 5th International Rice Genetics Symposium. Manila: IRRI; p. 44.

Varinruk B (2017) Thailand rice production and rice R\&D on climate change. In: Strengthening APEC cooperation on food security and climate change workshop, Hilton Hanoi opera hotel, Hanoi, Veit Nam 19-21 April 2017

Wang Y, Cao L, Zhang Y, Cao C, Liu F, Huang F, Qiu Y, Li R, Lou X (2015) Map-based cloning and characterization of $\mathrm{BPH} 29$, a B3 domain-containing recessive gene conferring brown planthopper resistance in rice. J Exp Bot 66: 6035-6045

Wongpanya R, Boonyalai N, Thammachuchourat N, Horata N, Arikit S, Myint KM, Vanavichit A, Choowongkomon K (2011) Biochemical and enzymatic study of rice $B A D H$ wild-type and mutants: an insight into fragrance in rice. Protein J 30:529-538

Wongsaprom C, Sirithunya P, Vanavichit A, Pantuwan G, Jongdee B, Sidhiwong N, Lanceras-Siangliw J, Toojinda T (2010) Two introgressed quantitative trait loc confer broad-spectrum resistance to blast disease in the genetic background of the cultivar RD6 Thai glutinous jasmine rice. Field Crops Res 119:245-251

Yoshihashi T, Nguyen TT, Kabaki N (2004) Area dependency of 2-acetyl-1-pyrroline content in an aromatic rice variety, Khao Dawk Mali 105. JARQ 38:105-109

Zhang J, Zheng HG, Aarti A, Pantuwan G, Nguyen TT, Tripathy JN, Sarial AK, Robin S, Babu RC, Nguyen BD, Sarkarung S, Blum A, Nguyen HT (2001) Locating genomic regions associated with components of drought resistance in rice: comparative mapping within and across species. Theor Appl Genet 103:19-29

Zhao Y, Huang J, Wang Z, Jing S, Wang Y, Ouyang Y, Cai B, Xin X-F, Liu X, Zhang C, Pan Y, Ma R, Li Q, Jiang W, Zeng Y, Shangguan X, Wang H, Du B, Zhu LXX, Feng Y-Q, He SY, Chen R, Zhang Q, He G (2016) Allelic diversity in an NLR gene BPH9 enables rice to combat planthopper variation. Proc Natl Acad Sci U S A 113:12850-12855

\section{Submit your manuscript to a SpringerOpen ${ }^{\circ}$ journal and benefit from:}

- Convenient online submission

- Rigorous peer review

- Open access: articles freely available online

- High visibility within the field

- Retaining the copyright to your article

Submit your next manuscript at $\gg$ springeropen.com 